\title{
Epidemiological profile of Echinococcosis in Morocco from 2014 to 2018: case of Tangier-Tetouan-Al Hoceima Region
}

\author{
Kaoutar Nabah ${ }^{1 *}$; Nadya Mezzoug ${ }^{2}$; Halima Oufdou ${ }^{3}$; Jamal Abrini² ${ }^{2}$ and Kacem Rharrabe ${ }^{1}$ \\ ${ }^{1}$ Abdelmalek Essaadi University. Polydisciplinary Faculty - Larache. Morocco. \\ ${ }^{2}$ Abdelmalek Essaadi University. Faculty of Sciences-Tetouan. Morocco. \\ ${ }^{3}$ Mohammed V University - Rabat. Morocco.
}

\begin{abstract}
In Morocco, the National Hydatidosis Control Program has approved considerable progress. However, updating epidemiological profile data of the disease is necessary. This study is carried out to explore the characteristics and epidemiological profile of Hydatidosis in Tangier-Tetouan-Al-Hoceima region. We conducted a retrospective descriptive study from 28 April 2019 to 18 February 2020. The data collected covering 2014-2018 period from the program reports. The statistical analysis was performed by EpiInfo 7. In total, 94 cases were notified. In 2015 , we recorded the highest incidence $(0.83$ cases $/ 100.000$ inhabitants). The highest percentage of patients was in Tetouan (28,7\%). 54.3\% of cases were women and $57.4 \%$ were from rural areas. The age of $47,3 \%$ of the cases was [18-40[years. The association between the professional status and sex was statistically significant $(\mathrm{p}<0.05) .94 .4 \%$ of cases, in the first stage of infection, were diagnosed by ultrasound. $84.7 \%$ presented hepatic localization. Almost all cases $(98.9 \%)$ were treated surgically. In conclusion, the National Hydatidosis Control Program should direct the actions in rural areas where the living conditions of the population are precarious. The study of canine Hydatidosis will also be necessary in the context of environmental health to carry out an integrated control for the human Hydatidosis disease.
\end{abstract}

\section{Introduction}

The Cystic Echinococcosis (CE) or Hydatidosis is classified by WHO as neglected tropical disease [1]. It's an Affection due to the development of Echinococci larval tapeworms of the genus Echinococcus [2]. When ingested by humans or other animals, this give birth in the stomach to the embryo or larva which, emigrating to other organs (liver, kidney, brain, etc.), this gives rise to cysts [2]. The hepatic localisation is the most common and treated by surgery in majority of cases [3-5]. A number of herbivorous and omnivorous animals acts as intermediate hosts of Echinococcus as well as dog which is final host [4].

Worldwide, even if $\mathrm{CE}$ is an neglected tropical disease, its still affect two to three million human cases (18,000 cases/year) specially in Italy, Greece, Bulgaria, Romania and Turkey [3] and caused over than $\$ 3$ billion as economic losses every year [5].

In Morocco, the Hydatidosis still be a public health problem. In 2017, 504 of cases were reported [6]. Other study reported a mean number of 37.1 of CE cases per year in some Moroccan endemic area [7] . On the other hand, It was reported that this zoonotic diseases affected the female sex, adult age, especially in rural and slums cities where the stray dog were present [8]. The

\footnotetext{
*Corresponding author: kaoutaysf@gmail.com
}

abundance of dog; the decreasing of knowledge level about infection; the inadequate and

lack of hygiene in abattoir are some risk factors responsible for maintaining the human and animal transmission of Echinococcus worldwide [9, 10].

This study describes the epidemiological profile of CE in the region of Tangier-Tetouan-Al Hoceima (TTA) during 2014- 2018 period to provide to the Hydatidosis national program some recommendation and measure to improving the fight against this disease.

\section{Materials and Methods}

This is a retrospective descriptive epidemiological study using a quantitative approach from 04/28/2019 to $02 / 18 / 2020$ in the TTA region. Data for 2014-2018 was collected from the annual reports of Cystic Echinococcosis health programme at the level of the Primary Health Care Network of the provincial Delegations of Health in the region.

Collected information included: age, gender, residence area, profession, active or passive surveillance, date of hospitalisation, date of living hospital, diagnosis techniques, location of the cyst and treatment methods including date of surgery. The frequency of $\mathrm{CE}$ cases during the study period has been calculated as well as all of other frequency of variables included in the study. Bivariate analysis was performed to identify the association between variables studied. The database was 
cleaned using Excel. Statistical analysis is performed by Epi-Info. Zotero (reference management) and NVIVO (contextual analysis of articles) software are used for bibliographic research.

\section{Results}

\subsection{Spatio-temporal repartition}

A total of 94 cases of CE were notified in our study. A number of 18[13-22] cases per years was notified passively. the geographic distribution characteristics of $\mathrm{CE}$ cases indicated that Tetouan province was the most affected by $28.7 \%$ (27) of the cases, followed by M'diqFnideq and Al Hoceima by $18.1 \%$ (16) and 16\% (16) respectively (Table 1).

The temporal repartition showed that the percentage of number of cases was 32\% (30) in 2015 and $23.4 \%$ (22) in 2014 with a peak of incidence of 0.8 cases $/ 100,000$ inhabitants in 2015 (Figure 1). The incidence observed between $2015(0.8 / 100,000$ inhabitants $)$ and 2018 $(0.5 / 100,000$ inhabitants) showed a decrease tendency during the period of our study (Figure 1).

\subsection{Socio-economic characteristics}

Socio-economic characteristics (Table 1) indicated that the cases were from rural areas (54.7\%) (Table 1).
The incidence of cases (cases/100,000 inhabitant) in the rural area was higher than the urban area throughout the duration of study but presenting decrease tendency in both environment area between 2014 and 2018 (Figure1).

Also, it was observed that females representing 54.3\% of the total cases reported (sex ratio $\mathrm{M} / \mathrm{F}=0,8)$ ). $\mathrm{CE}$ affected the adult age group of [18-40[ [years old at $47,3 \%$ (44) of the cases. The median of age was $22[16 ; 39]$ years old. $67.4 \%$ of the cases reported declared having a profession. The association between the profession and age $(\mathrm{p}=0.04)$ by Fisher-Exact test was significant as well as the association between the gender and profession ( $\mathrm{p}=0.001)$ by Khi2 test (Table 3 ).

\subsection{Clinical characteristics}

For the clinical characterises (Table 2), $94.4 \%$ of cases were in the first stage of infection, diagnosed by ultrasound $(81,9 \%)$ and scanner $(11,4 \%)$.

The patients with a hepatic localisation were for $84.7 \%$ of cases following by pulmonary localisation $(8.7 \%)$ and renal localisation $(3.3 \%)$. The surgery was the modality of treatment for all cases and all of them were recovered.

Finely, the median of hospital stay was $5[3 ; 8]$ days during the surgery (Table 2). with $1[0 ; 1,2]$ days before and $4[2 ; 6]$ days after the surgery (Table 2 ).

Table 1: The Spatio-temporal and socio-economic characteristics of EC cases in the TTA region; 2014-2018

\begin{tabular}{|c|c|c|}
\hline & Frequency & Percent $\%$ \\
\hline \multicolumn{3}{|l|}{ Province $(n=94)$} \\
\hline Al Hoceima & 15 & 16,0 \\
\hline Chefchaouen & 14 & 14,9 \\
\hline Fahse-Anjra & 2 & 2,1 \\
\hline M'diq-Fnideq & 17 & 18,1 \\
\hline Ouezzane & 12 & 12,8 \\
\hline Tangier-Assilah & 7 & 7,4 \\
\hline Tetouan & 27 & 28,7 \\
\hline \multicolumn{3}{|c|}{ Years of notification $(n=94)$} \\
\hline 2014 & 22 & 23,4 \\
\hline 2015 & 30 & 32,0 \\
\hline 2016 & 13 & 13,8 \\
\hline 2017 & 11 & 11,7 \\
\hline 2018 & 18 & 19,1 \\
\hline \multicolumn{3}{|c|}{ Age group (years) $(n=93)$} \\
\hline$[0-18[$ & 26 & 28,0 \\
\hline$[18-40[$ & 44 & 47,3 \\
\hline$[40-60[$ & 17 & 18,2 \\
\hline$\geq 60$ & 6 & 6,5 \\
\hline \multicolumn{3}{|l|}{ Gender $(n=94)$} \\
\hline Feminine & 51 & 54,3 \\
\hline Masculine & 43 & 45,7 \\
\hline \multicolumn{3}{|c|}{ Areas of residence $(n=94)$} \\
\hline Rural & 54 & 57,4 \\
\hline Urban & 40 & 42,6 \\
\hline \multicolumn{3}{|l|}{ Profession $(n=46)$} \\
\hline With & 31 & 67,4 \\
\hline Without & 15 & 22,6 \\
\hline
\end{tabular}


Table 2: Medical characteristics of EC cases in the TTA region; 2014-2018.

\begin{tabular}{|c|c|c|}
\hline & Frequency & percent $\%$ \\
\hline \multicolumn{3}{|l|}{ Diagnostic exam (n=94) } \\
\hline Ultrasound & 86 & 81,9 \\
\hline Scanner & 12 & 11,4 \\
\hline Radiography & 4 & 3,8 \\
\hline Serology test & 3 & 2,9 \\
\hline \multicolumn{3}{|l|}{ Cyst localisation $(n=92)$} \\
\hline Cervical & 1 & 1,1 \\
\hline Hepatic & 78 & 84,7 \\
\hline Pulmonary & 8 & 8,7 \\
\hline Renal & 3 & 3,3 \\
\hline Visceral & 2 & 2,2 \\
\hline \multicolumn{3}{|l|}{ Cyst stage $(n=90)$} \\
\hline Stage 1 & 85 & 94,4 \\
\hline Stage 2 & 3 & 3,4 \\
\hline Stage 3 & 2 & 2,2 \\
\hline Hospital stay $(n=92)$ & 5 days $[3 ; 7]$ & \\
\hline$>5$ days & 45 & 48,9 \\
\hline$\leq 5$ days & 47 & 51,1 \\
\hline Surgical delay* $(n=85)$ & 1 day $[0 ; 2]$ & \\
\hline$>1$ day & 23 & 27,1 \\
\hline$\leq 1$ day & 62 & 72,9 \\
\hline Postoperative delay** $(n=84)$ & 4 days $[2 ; 6]$ & \\
\hline$>4$ days & 32 & 38,1 \\
\hline$\leq 4$ days & 52 & 61,9 \\
\hline
\end{tabular}

* Delay between the date of hospitalisation and the date of the surgery

**Delay between the date of the surgery and discharge date from the hospital

Table 3: Association between age and gender with profession repartition of EC cases in the TTA region; 2014-2018.

\begin{tabular}{|c|c|c|c|}
\hline & \multicolumn{2}{|c|}{$\begin{array}{c}\text { Profession } \\
\text { Frequency (\%) }\end{array}$} & \multirow[b]{2}{*}{ p-value } \\
\hline & With & Without & \\
\hline $\begin{array}{l}\text { Age group } \\
\text { (vears) }\end{array}$ & $\mathrm{n}=15$ & $\mathrm{n}=31$ & 0,04 \\
\hline$[0-20[$ & $4(26,7)$ & $6(19,4)$ & \\
\hline$[20-40[$ & $8(53,3)$ & $17(54,8)$ & \\
\hline$[40-60[$ & $2(13,3)$ & $7(22,6)$ & \\
\hline$\geq 60$ & $1(6,7)$ & $1(3,2)$ & \\
\hline Total & $15(32,6)$ & $31(67,4)$ & \\
\hline Gender & $\mathrm{n}=15$ & $\mathrm{n}=31$ & 0,001 \\
\hline Female & $5(33,4)$ & $23(74,2)$ & \\
\hline Mal & $10(66,6)$ & $8(25,8)$ & \\
\hline Total & $15(32,6)$ & $31(67,4)$ & \\
\hline
\end{tabular}

*Corresponding author: kaoutaysf@gmail.com 


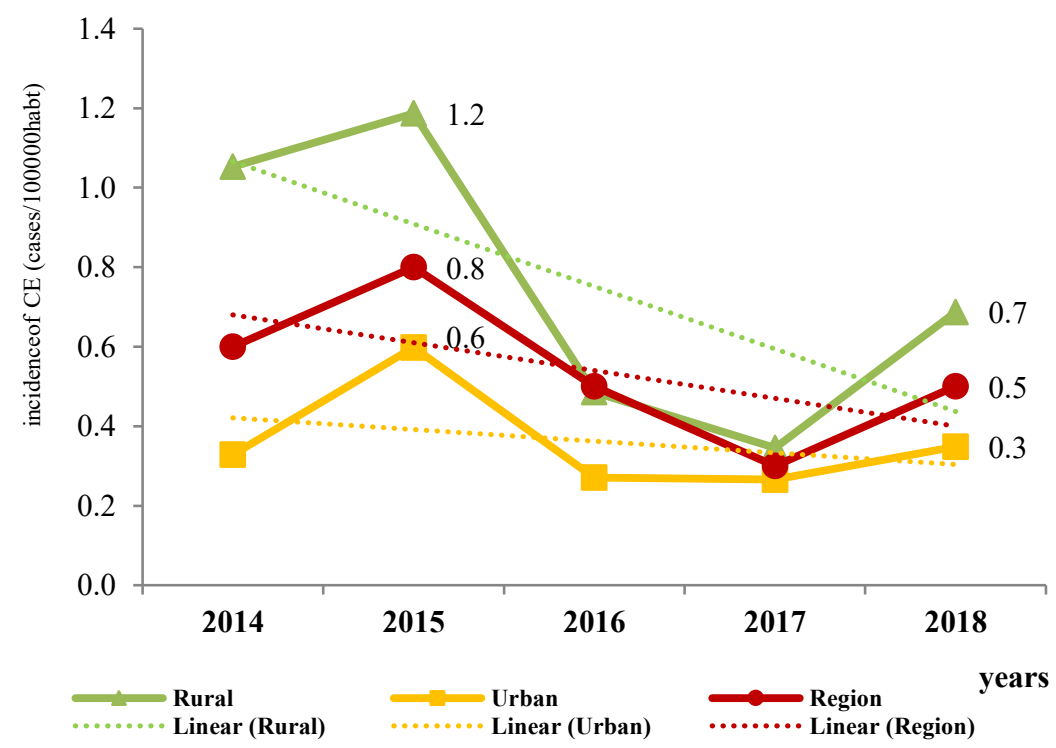

Fig. 1. Distribution of general incidence and incidence by area of residence of CE cases in the TTA region; 2014-2018.

\section{Discussion}

Cystic echinococcosis caused by infection with the larval stage of Echinococcus granulosus is found in Africa, Europe, Asia, the Middle East, Central and South America, and in rare cases, North America [11]. Thus, our study showed that CE cases continue to be reported in the north region of Morocco during a period of 2014-2018. The number of cases per year reported was 18[13-22] cases. This number still be inferior to the number of cases reported (average of 37.1 cases/year) in other study carried out in a the south region of morocco between 2010 and 2016 [8]. However, this frequency of CE cases may not reflect the real occurrence of the disease in our region. This will be due to underreporting since the surveillance of all cases included in this study was a passive surveillance.

The incidence observed in our study present a decrease tendency between 2015 and 2018 ( 0.8 to 0.5 cases/100,000 inhabitant) in opposite of the increase of this incidence reported in Morocco in 1980 to 2008 (3.6 to 5.2 cases / 100,000 inhabitant) [12]. The rural areas was the environment the most affected in our region as well as in other region of Morocco [8] and other countries in Europe, Middle East and Asia [4, 13, 15].

As its know, the CE cycle transmission include sheep, goats, cattle and dogs as final host [16]. In Morocco, it was reported that $35.3 \%$ of dogs was infected, specially in rural area with a slaughterhouses where the prevalence of dog infected risen to $62,7 \%$ [17]. This is explaining partially the persistence of infection in the rural area. Moreover, this could be due also to the illiteracy risk factor causing a lack of information about the $\mathrm{CE}$ among the rural population $[9,10]$. In addition, it was reported that the poor hygiene give rise to the contamination of water and vegetables by eggs of EC in the fields by dog excrement in the proximity of the owners of the cattle and dogs in the rural area $[9,18]$.
In our study, most cases affected were adults. This was reported in many other studies in Morocco as well as countries from Mediterranean region, Middle East and Asia $[8,14,19,20,21,22]$. Infantile age has also been observed in our results knowing that $10 \%$ to $20 \%$ of CE cases $\leq 16$ years can be detected in childhood because of the rapid development of infection at an early age in some cases[23].

The female were more affected then males in our results in agreement with other studies from Morocco and many other countries [8, 14, 20, 24-27]. This could be associated with the work performed by women as cooking activities (attitudes of tasting raw vegetables) [8]; cleaning milking (ruminant animals) and feeding dogs and cattle [14]. In contrary, the males were the most affected in some other studies performed in Turkey and Iran $[22,28]$.

The Hepatic localization is the most frequent in several studies as well as our study [3-25-29]. Also, as it's known, the stage depends on the time of diagnosis, the onset of disease and subclinical evolution of the cyst [29]. Our results showed that the most cases were on primary stage as well it was reported before in the literature [11, $25]$.

Finally, the hospital stay in our investigation (5 days[3-7]) was proximally the same reported in other study in the south region of Morocco (5.5 days)[8]. This duration was less than the period found on other results from studies carried out in Iran (25 day) and Romania (more than 13,4 days) [30,31].

\section{Conclusion}

This study allows us to describe the epidemiological profile of Cystic Echinococcosis in the north region of Morocco. This is the first study, to our knowledge, carried 
out in this region ever and showing a decrease on the frequency of the disease during the study duration.

To improve the Hydatidosis control, Health education and participation of the populations in the fight against the disease is essential measure. In addition, the Hydatidosis control program must direct its actions also on the fight against the terminal hosts (dogs) meanly in the rural areas. Those control measures must be established in multidisciplinary approach integrating the various environmental and health stakeholders to achieve the goal of CE eradication from Morocco.

\section{References}

1. World Health Organization, Ending the neglect to attain the Sustainable Development Goals: A road map for neglected tropical diseases 2021-2030. (2021).

2. I. Marroun, J. Quevaulliers, T. Sené, and A. Fingerhut, " $E$ ", in New Medical Dictionary (Seventh Edition), (Elsevier Masson, Paris, 2018).

3. Anofel et al., Chapitre 35 - Cestodoses larvaires : Échinococcoses (hydatidose et échinococcose alvéolaire), cysticercose et cestodoses larvaires rares, in Parasitologie et Mycologie Médicales Guide des Analyses et des Pratiques Diagnostiques, (Elsevier Masson, Paris, 2017).

4. O. Bouchaud, P.-H. Consigny, M. Cot, G. Le Loup, S. Odermatt-Biays, 12 - Fiches maladies, " in Médecine des Voyages et Tropicale (Quatrième Édition), (Elsevier Masson, Paris, 2019)

5. N. I. Agudelo Higuita, E. Brunetti, and C. McCloskey, Cystic Echinococcosis, J. Clin. Microbiol, 4, 3(2016).

6. Ministère de la Santé, santé en chiffre 2017, Rabat. Maroc. (2018).

7. I. El Berbri, A. F. Petavy, G. Umhang, M. Bouslikhane, O. Fassi Fihri, F. Boué, A. Dakkak, Epidemiological investigations on cystic echinococcosis in North-West (Sidi Kacem Province) Morocco : infection in ruminants, Adv. Epidemiol, (2015).

8. O. Amahmid, Y. El Guamri, K. Zenjari, S. Bouhout, MA. Moh, F. Boraam, A. Melloul, B. Benfaida, K. Bouhoum, D. Belghyti, Epidemiology and clinical features of human cytic echinococcosis in adults from an endemic area (Morocco), Clin. Epidémioly. Glob. Health 8, 2(2020)

9. I. El Berbri, MJ. Ducrotoy, AF. Petavy, O. Fassifihri, AP. Shaw, M. Bouslikhane, S. Boue, S. Welburn, A. Dakkak, Knowledge, attitudes and practices with regard to the presence, transmission, impact, and control of cystic echinococcosis in Sidi Kacem Province, Morocco, Infect. Dis. Poverty 4 (2015).

10. A. Dakkak, Echinococcosis/hydatidosis : A severe threat in Mediterranean countries, Vet. Parasitol 174, 1-2(2010).

11. Center for Diseasis contrôle and Prevention, Echinococcosis - Epidemiology \& Risk Factors, (2012).

https://www.cdc.gov/parasites/echinococcosis/epi. html (accessed Jun. 12, 2021).
12. O. Derfoufi, A. Elmaataoui, E. Miss, H. Esselmani, M. Lyagoubi, M, S. Aoufi, Epidemiological profile of cystic echinococcosis in Morocco from 1980 to 2008, Ann. Biol. Clin 70, 4 (2012).

13. B. Chakarova, K. Kichukova, G. Rasheva, Z. Naneva, E. Kaneva, T. Perchemlieva, S. Sabeva, $A$ short overview of the cystic echinococcosis among people in Bulgaria and Stara Zagora region during the period 2006-2014, Trakia J Sci 13, 2(2015).

14. T. Zhang, W. Zhao, D. Yang, D. Piao, S. Huang, Y. Mi, Y. Zhao, J. Cao, Y. Shen, W. Zhang, A. Liu, Human cystic echinococcosis in Heilongjiang Province, China : a retrospective study, BMC Gastroenterol 15, 29(2015).

15. N. Fallah, K. Rahmati, M. Fallah, Prevalence of Human Hydatidosis Based on Hospital Records in Hamadan West of Iran from 2006 to 2013, Iran J Parasitol 12, 3(2017).

16. P. Deplazes, L. Rinaldi, C. A. Alvarez Rojas, P. R. Torgerson, M. F. Harandi, T. Romig, D. Antolova, J. Schurer, S. Lahmar, G. Cringoli, R. C. A. Thompson, E. J . Jenkins, Chapter Six - Global Distribution of Alveolar and Cystic Echinococcosis, in Advances in Parasitology 95, (Academic Press, 2017).

17. A. Dakkak, I. El Berbri, AF. Petavy, F. Boué, M. Bouslikhane, O. F. Fihri, S. Welburn, MJ. Ducrotoy, Echinococcus granulosus infection in dogs in Sidi Kacem Province (Northwest Morocco), Acta. Trop 165, (2017).

18. P. Veit, B. Bilger, V. Schad, J. Schäfer, W. Frank, and R. Lucius, Influence of environmental factors on the infectivity of Echinococcus multilocularis eggs, Parasitology 110, (1995).

19. S. Mousavi, M. Samsami, M. Fallah, H. Zirakzadeh, A retrospective survey of human hydatidosis based on hospital records during the period of 10 years, J. Parasit. Dis 36, (2012).

20. S. Lahmar, W. Rebaï, B. S. Boufana, P. S. Craig, R. Ksantini, A. Daghfous, F. Chebbi, H. Bedioui, Z. Ben Safta, Cystic echinococcosis in Tunisia : analysis of hydatid cysts that have been surgically removed from patients, Ann. Trop. Med. Parasitol 103, 7(2009).

21. M. A. Lupu, A. Dragomir, A. A. Paduraru, S. A. Ritiu, F. Lazar, S. Olariu, D. Valceanu, O. N. Burlacu, O.M. Cretu, Cystic echinococcosis in adult hospitalized patients : A 10-year retrospective study in Western Romania, Int. J. Infect. Dis 73, (2018).

22. M. Aksu, F. K. Sevimli, I. Ibiloglu, R. B. Arpaci, Cystic echinococcosis in the Mersin province (119 cases), Türkiye. Parazitolojii. Dergisi 37, 4(2013).

23. T. Yoshida, T. Kamiyama, T. Okada, K. Nakanishi, H. Yokoo, H. Kamachi, M. Matsushita, N. Sato, F. Sasaki, S. Todo, Alveolar echinococcosis of the liver in children, J. HepatoBiliary. Pancreat. Sci 17, 2 (2010).

24. K. M. Al-Qaoud, P. S. Craig, and S. K. Abdel-Hafez, Retrospective surgical incidence and case 
distribution of cystic echinococcosis in Jordan between 1994 and 2000, Acta. Trop 87, 2(2003).

25. E. L. S. Romani, R. Rodrigues-Silva, A. Maldonado, J. R. Machado-Silva, D. C. Gomes, Notes on human cases of cystic echinococcosis in Peru, Mem. Inst. Oswaldo Cruz 101, 3(2006).

26. I. Colovic Calovski, A. Barac, Z. Golubovic, A. Karamarkovic, S. Mitrovic, M. Milicevic, M. Cvetkovic, A. M. Dzamic, Case-series study of hepatic echinococcal cysts in Serbia : viability of scolices, seropositivity and epidemiological characteristics, J. Helminthol 92, 2(2018).

27. H. M. Hajipirloo, A. Bozorgomid, T. Alinia, K. H. Tappeh, R. Mahmodlou, Human Cystic Echinococcosis in West Azerbaijan, Northwest Iran : A Retrospective Hospital Based Survey from 2000 To 2009, Iran J Parasitol 8, 2(2013). in Hamadan West of Iran from 2006 to 2013, Iran J Parasitol 12, 3(2017).

29. E. Brunetti, P. Kern, D. A. Vuitton, Expert consensus for the diagnosis and treatment of cystic and alveolar echinococcosis in humans, Acta. Trop 114, 1(2010)

30. D. C. Vlad, A. M. Neghina, V. Dumitrascu, I. Marincu, R. Neghina, C. L. Calma, Cystic echinococcosis in children and adults : a sevenyear comparative study in western Romania, Foodborne Pathog. Dis 10, 2 (2013).

31. N. Nourjah, G. Sahba, M. Baniardalani, A. Chavshin, Study of 4850 operated hydatidosis cases in Iran, Southeast Asian J. Trop. Med. Public Health 35, 1(2004).
28. N. Fallah, K. Rahmati, M. Fallah, Prevalence of 3.0Human Hydatidosis Based on Hospital Records 